\title{
Perioperative allogenic blood transfusion increases the incidence of postoperative deep vein thrombosis in total knee and hip arthroplasty
}

Tao Jiang ${ }^{1,2+}$, Kai Song ${ }^{1,2+}$, Yao Yao ${ }^{1,2}$, Pin Pan ${ }^{1,2}$ and Qing Jiang ${ }^{1,2^{*}}$ (D)

\begin{abstract}
Background: Excessive blood loss caused by total joint arthroplasty (TJA) often increases the requirement for blood transfusion, which is associated with adverse outcomes. The purpose of this study was to determine the relationship between perioperative transfusion and postoperative DVT in TJA.

Methods: This retrospective study reviewed medical records of 715 patients, who consecutively underwent primary unilateral total knee arthroplasty (TKA) or total hip arthroplasty (THA) at our institution between September 2015 and March 2017. Demographic, clinical and surgical parameters were introduced into the univariate analysis to find risk factors for DVT within postoperative 30 days. In order to identify if allogenic blood transfusion was independently associated with DVT, a multivariate logistic regression analysis was conducted to adjust for gender, age, body mass index (BMI), diagnosis, and type of surgery.

Results: The incidence of perioperative allogenic blood transfusion was $12.4 \%(n=89)$. Fifty-seven patients (8.0\%) developed DVT after surgery. Univariate analysis demonstrated that there were differences between DVT group and non-DVT group in gender $(P=0.045)$, age $(P<0.001)$, BMI $(P=0.026)$, primary diagnosis $(P=0.001)$, type of surgery $(P<0.001)$, and transfusion rates $(P=0.040)$. After adjustment by using multivariate logistic regression analysis, transfusion appeared to be the independent risk factor for DVT in TJA ( $P=0.001 ; \mathrm{OR}=3.9,95 \% \mathrm{Cl} 1.8-8.4)$.

Conclusion: We found that perioperative allogenic blood transfusion was significantly associated with DVT following TJA. In order to reduce the risk of DVT and other adverse outcomes, methods to decrease transfusion rates should be used in clinical practice.
\end{abstract}

Keywords: Allogenic blood transfusion, Deep vein thrombosis, Total knee arthroplasty, Total hip arthroplasty

\section{Introduction}

Total joint arthroplasty (TJA) can cause substantial blood loss, which increases the risk of blood transfusion during the perioperative period. The reported transfusion rates are $11.0-19.6 \%$ in total knee arthroplasty (TKA) and

\footnotetext{
*Correspondence: qingj@nju.edu.cn

${ }^{\dagger}$ Tao Jiang and Kai Song contribute equally to this research and share joint first authorship.

'State Key Laboratory of Pharmaceutical Biotechnology, Department of Sports Medicine and Adult Reconstructive Surgery, Nanjing Drum Tower Hospital, The Affiliated Hospital of Nanjing University Medical School, 321 Zhongshan Road, Nanjing 210008, Jiangsu, People's Republic of China ${ }^{2}$ Laboratory for Bone and Joint Disease, Model Animal Research Center (MARC), Nanjing University, Nanjing 210093, Jiangsu, People's Republic of China
}

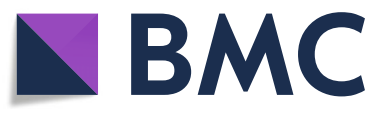

(C) The Author(s). 2019 Open Access This article is distributed under the terms of the Creative Commons Attribution 4.0 International License (http://creativecommons.org/licenses/by/4.0/), which permits unrestricted use, distribution, and reproduction in any medium, provided you give appropriate credit to the original author(s) and the source, provide a link to the Creative Commons license, and indicate if changes were made. The Creative Commons Public Domain Dedication waiver (http://creativecommons.org/publicdomain/zero/1.0/) applies to the data made available in this article, unless otherwise stated. $[1,2]$. Patients receiving transfusion during TJA are at higher risk of surgical site infection, cardiopulmonary complications, prolonged length of hospitalization, increased costs, and even mortality [3, 4].

Transfusion has also proven to be associated with postoperative deep vein thrombosis (DVT) in fields outside of orthopedics, including general surgery [5], urology [6], cardiac surgery [7], vascular surgery [8], obstetrics, and gynecology $[9,10]$. In patients with isolated orthopedic trauma, the transfusion of packed red blood cell is the risk factor for venous thromboembolism (VTE) [11]. Transfusion has also been reported to 
increase the risk of DVT in patients undergoing spine surgeries [12-15].

DVT represents a common complication after TJA and can lead to adverse clinical outcomes, especially life-threatening pulmonary embolism (PE). Numerous relevant risk factors have been identified, including older age, obesity, metabolic syndrome, cardiovascular disease, previous thrombosis history, and a high American Society of Anesthesiologists (ASA) grade [16-19]. However, the relationship between transfusion and DVT in TJA is rarely studied. Therefore, we conducted this retrospective study to determine the association between perioperative allogenic blood transfusion and DVT after TKA and THA.

\section{Methods}

This retrospective study was approved by our institutional review board (IRB). We enrolled consecutive patients undergoing primary unilateral TKA or THA at our institution between September 2015 and March 2017. If a patient received staged bilateral arthroplasties during the research period, only the first procedure was included. We excluded patients with coagulation disorders or established DVT prior to surgery.

If patients were bedridden for more than $48 \mathrm{~h}$ due to femoral neck fracture, preoperative anticoagulants were used. For the other patients, we did not routinely perform thromboprophylaxis before surgery. If patients had been taking aspirin for cardiovascular diseases, they did not need to stop it before surgery. All surgeries were conducted under general anesthesia by 4 surgeons. TKA was performed using medial parapatellar arthrotomy. A pneumatic tourniquet was inflated before skin incision and deflated immediately after cementing the prosthesis. The modified Hardinge approach was employed in THA, and we routinely used a cementless prosthesis. Intravenous tranexamic acid (TXA) was used before tourniquet release in TKA and skin incision in THA.

We used rivaroxaban (10 mg once daily) or low-molecular-weight heparin (LMWH) (30 mg once daily) to prevent DVT after surgery. However, chemical thromboprophylaxis might not be considered if intraoperative excessive blood loss or great amount of postoperative drainage occurred. Additionally, intermittent pneumatic compression devices were applied, and patients were encouraged to do ankle pump exercises during the postoperative period. All patients' both lower limbs were screened for DVT by Doppler ultrasound within 3-5 days after surgery. If patients visited outpatient clinic with DVT-related symptoms after discharge, evaluation of DVT with ultrasound was also performed. All events of symptomatic and asymptomatic DVT within postoperative 30 days were recorded. If a proximal DVT was diagnosed, a thrombolytic dose of rivaroxaban $(10 \mathrm{mg}$ twice daily) was applied. For patients diagnosed with distal DVT, the prolonged use of anticoagulants was adopted. Inferior vena cava filter was not used in any of the patients in this study.

During the operation, blood transfusion was performed if the level of hemoglobin $(\mathrm{Hb})$ decreased lower than $9.0 \mathrm{~g} / \mathrm{dL}$. After the operation, patients received blood transfusion if their levels of $\mathrm{Hb}$ were less than 8.0 $\mathrm{g} / \mathrm{dL}$, or if they developed obvious anemic symptoms with a $\mathrm{Hb}$ level of less than $9.0 \mathrm{~g} / \mathrm{dL}$. None of the patients in this study received allogenic blood transfusion or underwent autologous blood predonation before surgery.

Patients' demographic, clinical, and surgical information was collected. Patients were divided into DVT group and non-DVT group. We compared the differences between these two groups in gender, age, body mass index (BMI), coexisting illnesses, previous surgeries in ipsilateral lower extremity, preoperative medication, smoking history, primary diagnosis, type of surgery (TKA or THA), operation time, amount of intraoperative blood loss, postoperative anticoagulants, and transfusion rates. Qualitative variables were analyzed by a chi-square test and quantitative variables were analyzed by a $t$ test. In order to determine if transfusion was independently associated with DVT, a multivariate logistic regression analysis was employed to adjust for gender, age, BMI, diagnosis, and type of surgery. All the statistical analysis was done using STATA version 12.0 (Stata Corp. LP, College Station, TX, USA).

\section{Results}

A total of 715 patients were enrolled with a mean age of 65.1 \pm 12.6 years (range 21-94 years). There were 208 males and 507 females. Three hundred and nineteen patients underwent TKA for osteoarthritis (OA) or rheumatoid arthritis (RA), and 396 patients underwent THA for OA, RA, femoral neck fracture, osteonecrosis of the femur head, developmental dysplasia of the hip, or ankylosing spondylitis affecting hips. Table 1 shows the characteristics of these patients.

Eighty-nine patients (12.4\%) received allogenic blood transfusion during perioperative period. Among them, 15 patients were only transfused intraoperatively, 69 patients were only transfused postoperatively, and 5 patients were transfused both intraoperatively and postoperatively. Separately, the incidence of transfusion was $6.6 \%(n=21)$ in TKA and $17.2 \%(n=68)$ in THA, respectively.

DVT was developed in $8.0 \%$ of these patients $(n=57)$. There were 3 proximal DVTs and 54 distal DVTs. Six patients had thrombi in the intramuscular venous plexus of both lower limbs, the others developed thrombi only in the operated legs. Among the patients diagnosed with 
Table 1 Demographic, clinical, and surgical characteristics of the patients

\begin{tabular}{|c|c|c|c|}
\hline Characteristics & $\begin{array}{l}\text { Total } \\
(n=715)\end{array}$ & $\begin{array}{l}\text { TKA } \\
(n=319)\end{array}$ & $\begin{array}{l}\text { THA } \\
(n=396)\end{array}$ \\
\hline \multicolumn{4}{|l|}{ Gender } \\
\hline Male (\%) & $208(29.1)$ & $58(18.2)$ & $150(37.9)$ \\
\hline Female (\%) & $507(70.9)$ & $261(81.8)$ & $246(62.1)$ \\
\hline Age, years (mean $\pm S D$ ) & $65.1 \pm 12.6$ & $67.5 \pm 9.2$ & $63.2 \pm 14.5$ \\
\hline $\mathrm{BMI}, \mathrm{kg} / \mathrm{m}^{2}($ mean $\pm \mathrm{SD})$ & $24.7 \pm 4.3$ & $26.1 \pm 4.1$ & $23.5 \pm 4.0$ \\
\hline Diabetes (\%) & $116(16.2)$ & 69 (21.6) & $47(11.9)$ \\
\hline Hypertension (\%) & $322(45.0)$ & $178(55.8)$ & $144(36.4)$ \\
\hline Malignance (\%) & $30(4.2)$ & $13(4.1)$ & $17(4.3)$ \\
\hline Cardiovascular disease (\%) & $84(11.7)$ & $40(12.5)$ & $44(11.1)$ \\
\hline Stroke (\%) & $95(13.3)$ & $48(15.0)$ & $47(11.9)$ \\
\hline COPD (\%) & $11(1.5)$ & $5(1.6)$ & $6(1.5)$ \\
\hline Venous disease (\%) & $24(3.4)$ & $16(5.0)$ & $8(2.0)$ \\
\hline Previous surgery (\%) & $18(2.5)$ & $1(0.3)$ & $17(4.3)$ \\
\hline Preoperative aspirin (\%) & 99 (13.8) & $52(16.3)$ & $47(11.9)$ \\
\hline Preoperative steroid (\%) & $27(3.8)$ & $7(2.2)$ & $20(5.1)$ \\
\hline Smoking (\%) & $91(12.7)$ & $23(7.2)$ & $68(17.2)$ \\
\hline \multicolumn{4}{|l|}{ Diagnosis } \\
\hline $\mathrm{OA}(\%)$ & $333(46.6)$ & $292(91.5)$ & $41(10.4)$ \\
\hline RA (\%) & $36(5.0)$ & $27(8.5)$ & $9(2.3)$ \\
\hline Femoral neck fracture (\%) & $133(18.6)$ & - & 133 (33.6) \\
\hline ONFH (\%) & $145(20.3)$ & - & $145(36.6)$ \\
\hline $\mathrm{DDH}(\%)$ & $60(8.4)$ & - & $60(15.2)$ \\
\hline AS (\%) & $8(1.1)$ & - & $8(2.0)$ \\
\hline $\begin{array}{l}\text { Operation time, min } \\
\text { (mean } \pm \text { SD) }\end{array}$ & $109.7 \pm 29.0$ & $119.4 \pm 22.0$ & $101.9 \pm 31.4$ \\
\hline $\begin{array}{l}\text { Intraoperative blood loss, } \\
\mathrm{ml}(\text { mean } \pm \text { SD) }\end{array}$ & $258.8 \pm 208.8$ & $200.3 \pm 136.3$ & $306.0 \pm 242.5$ \\
\hline \multicolumn{4}{|l|}{ Chemical thromboprophylaxis } \\
\hline None (\%) & $28(3.9)$ & $10(3.1)$ & $18(4.5)$ \\
\hline Rivaroxaban (\%) & $599(83.8)$ & $279(87.5)$ & $320(80.8)$ \\
\hline LMWH (\%) & $88(12.3)$ & $30(9.4)$ & $58(14.6)$ \\
\hline
\end{tabular}

a TKA total knee arthroplasty, THA total hip arthroplasty, SD standard deviation, $B M I$ body mass index, $C O P D$ chronic obstructive pulmonary disease, $O A$ osteoarthritis, RA rheumatoid arthritis, ONFH osteonecrosis of the femur head, $D D H$ developmental dysplasia of the hip, AS ankylosing spondylitis, $L M W H$ low-molecular-weight heparin

DVT, 15 presented with DVT-related symptoms, the others were diagnosed with asymptomatic DVT by regular ultrasound screening. The DVT rates in TKA and THA were $13.2 \%(n=42)$ and $3.8 \%(n=15)$, respectively.

According to univariate analysis for total patients, there were statistically significant differences in gender $(P=0.045)$, age $(P<0.001)$, BMI $(P=0.026)$, primary diagnosis $(P=0.001)$, type of surgery $(P<0.001)$, and transfusion rates $(P=0.040)$ between DVT group and non-DVT group (Table 2). The subsequent multivariate
Table 2 Univariate analysis of the risk factors for DVT in TJA

\begin{tabular}{llll}
\hline Variable & $\begin{array}{l}\text { Non-DVT } \\
(n=658)\end{array}$ & $\begin{array}{l}\text { DVT } \\
(n=57)\end{array}$ & $P$ value \\
\hline Female gender (\%) & $460(69.9)$ & $47(82.5)$ & $0.045^{*}$ \\
Age, years (mean \pm SD) & $64.7 \pm 12.8$ & $70.6 \pm 8.8$ & $<0.001^{*}$ \\
BMl, kg/m ${ }^{2}$ (mean \pm SD) & $24.6 \pm 4.2$ & $25.9 \pm 4.4$ & $0.026^{*}$ \\
Diabetes (\%) & $110(16.7)$ & $6(10.5)$ & 0.224 \\
Hypertension (\%) & $291(44.2)$ & $31(54.4)$ & 0.139 \\
Malignance (\%) & $29(4.4)$ & $1(1.8)$ & 0.338 \\
Cardiovascular disease (\%) & $77(11.7)$ & $7(12.3)$ & 0.896 \\
Stroke (\%) & $84(12.8)$ & $11(19.3)$ & 0.163 \\
COPD (\%) & $10(1.5)$ & $1(1.8)$ & 0.890 \\
Venous disease (\%) & $23(3.5)$ & $1(1.8)$ & 0.484 \\
Previous surgery (\%) & $18(2.7)$ & $0(0)$ & 0.206 \\
Preoperative aspirin (\%) & $92(14.0)$ & $7(12.3)$ & 0.721 \\
Preoperative steroid (\%) & $27(4.1)$ & $0(0)$ & 0.119 \\
Smoking (\%) & $86(13.1)$ & $5(8.8)$ & 0.350 \\
Diagnosis & - & - & $0.001^{*}$ \\
TKA (\%) & $277(42.1)$ & $42(73.7)$ & $<0.001^{*}$ \\
Operation time, min (mean \pm SD) & $109.9 \pm 29.3$ & $107.7 \pm 24.2$ & 0.585 \\
Intraoperative blood loss, & $262.9 \pm 213.5$ & $211.8 \pm 136.2$ & 0.076 \\
ml (mean \pm SD) & & & 0.185 \\
Chemical thromboprophylaxis & - & - & $0.040^{*}$ \\
\hline Transfusion (\%) & $77(11.7)$ & $12(21.1)$ & \\
\hline P<0.05 was consin & & & \\
\hline
\end{tabular}

${ }^{*} P<0.05$ was considered statistically significant

${ }^{a} D V T$ deep vein thrombosis, $T J A$ total joint arthroplasty, $S D$ standard deviation, $B M I$ body mass index, COPD chronic obstructive pulmonary disease, TKA total knee arthroplasty

logistic regression analysis showed that transfusion was the independent risk factor for postoperative DVT $(P=$ $0.001 ;$ OR $=3.9,95 \%$ CI 1.8-8.4) after adjustment for gender, age, BMI, primary diagnosis, and type of surgery (Table 3).

In TKA group, we did not find risk factors for DVT. The incidence of transfusion was numerically higher in DVT group than that in non-DVT group $(11.9 \%$ vs. $5.8 \%)$, but this difference was not statistically significant $(P=0.136)$.

Table 3 Multivariate logistic regression analysis to identify the independent risk factors for DVT in TJA

\begin{tabular}{llll}
\hline & OR & $95 \% \mathrm{Cl}$ & $P$ value \\
\hline Female & 1.395 & $0.669-2.911$ & 0.375 \\
Age & 1.051 & $1.019-1.084$ & 0.002 \\
BMI & 1.059 & $0.989-1.135$ & 0.102 \\
Diagnosis & - & - & 0.888 \\
TKA & 4.221 & $0.492-36.226$ & 0.189 \\
Transfusion & 3.887 & $1.789-8.446$ & 0.001 \\
\hline
\end{tabular}

${ }^{*} P<0.05$ was considered statistically significant

${ }^{a} D V T$ deep vein thrombosis, $T J A$ total joint arthroplasty, $O R$ odds ratio, $C I$ confidence interval, $B M I$ body mass index, TKA total knee arthroplasty 
In THA group, gender $(P=0.011)$, age $(P=0.005)$, and transfusion $(P=0.002)$ were found to be associated with postoperative DVT in univariate analysis. After adjustment for gender, age, BMI, and diagnosis, transfusion appeared to be the independent risk factor for postoperative DVT $(P=0.011$; OR $=4.3,95 \%$ CI $1.4-12.9)$.

\section{Discussion}

In this study, we retrospectively studied 718 patients undergoing primary unilateral TKA or THA to explore the relationship between perioperative allogenic blood transfusion and DVT within postoperative 30 days. We attempted to introduce as many potential confounders as possible into the analysis to clarify the correlation. Transfusion was found to be significantly associated with DVT following TJA. Patients receiving blood transfusion had a four times greater risk of postoperative DVT.

According to the limited existing evidence, the relationship between blood transfusion and postoperative DVT in TJA remains controversial. Gray et al. [20] conducted a study involving patients receiving elective THA, and revealed a higher incidence of blood transfusion in those with DVT. Additionally, Danninger et al. [21] analyzed the outcomes of blood transfusion in TKA and THA, and found transfusion increased the risk of postoperative DVT. However, Frisch et al. [22] did not find the relationship between transfusion and DVT in their patients undergoing TKA and THA. Therefore, more studies with larger sample size and longer follow-up time regarding this topic are required.

Blood transfusion can alter the local hemorheology and increase blood viscosity, which causes red blood cell (RBC) aggregation, and subsequent thrombus formation [23]. In addition, patients present with a hyper-inflammatory and hypercoagulable state after TJA. Transfusion stimulates neutrophils to release inflammatory cytokines such as IL-8 and sPLA2 [24]. The proinflammatory nature of allogenic blood transfusion may further increase the risk of thrombosis. It is also demonstrated that the transfusion of RBC can increase platelet aggregation [25], which may play a role in DVT formation. Besides, stored RBCs release free hemoglobin and microparticles, which decrease the level of nitric oxide and cause vasoconstriction [26]. Spinella et al. [27] performed a study to explore the effects of RBC storage duration on the incidence of DVT in patients with traumatic injuries, and found that the transfusion of RBC with a storage age of more than 28 days increased the risk of DVT significantly.

Apart from the risk of allergy and transmitted diseases, blood transfusion also increases the risk of adverse outcomes, longer length of stay, increased costs, and discharge to short-term care in patients undergoing TJA
[28]. This study shows that transfusion is also the risk factor for postoperative DVT. Given the numerous latent risks of transfusion, it is critical to identify the patients at high risk of transfusion and to employ measures to reduce transfusion rates in TJA. Preoperative low level of $\mathrm{Hb}$ is strongly associated with postoperative transfusion [29-31]. Therefore, preoperative hemoglobin optimization has got widespread attention. Erythropoietin and iron supplementation have proven to be effective in decreasing the requirement of transfusion in TJA [32, 33]. Autologous blood predonation is also a useful preoperative strategy to reduce the need for allogenic transfusion $[34,35]$. During the surgery, there are several methods to decrease blood loss, including the use of antifibrinolytic agents (TXA and aminocaproic acid), locally applied hemostatic agents (fibrin sealant and bone wax), and computer navigation [36-40]. In addition, intraoperative and postoperative blood salvages are used to decrease the need for and quantity of allogenic transfusion [41, 42]. However, blood salvage does not reduce allogenic transfusion rates in patients with a preoperative $\mathrm{Hb}$ level of less than $12 \mathrm{~g} / \mathrm{dL}$ [43], so a combination of preoperative optimization should be considered in these patients.

It should be noted that this study has the limitations inherent to retrospective single-center study. There are still other confounders not introduced into the analysis due to the retrospective nature of this study. We excluded patients with coagulation disorders from this study. However, patients enrolled in this study may have other types of blood abnormality, such as anemia. Additionally, the small sample size did not allow us to perform subgroup analysis about the effects of doses or types of blood products on the incidence of DVT. There was a higher transfusion rate in THA group despite using TXA in this study compared to that in other studies, which may be caused by different blood management strategies. In this study, we only analyzed the DVTs occurring within postoperative 30 days. Those occurring outside of the period were not included in this study. There were only three patients diagnosed with proximal DVTs, and they did not receive blood transfusion during perioperative period. However, we cannot determine the relationship between blood transfusion and proximal DVTs due to such a small sample size.

\section{Conclusion}

This study demonstrated the relationship between perioperative allogenic blood transfusion and postoperative DVT in patients undergoing primary unilateral TKA and THA. In order to reduce the risk of DVT and other adverse outcomes, strategies to decrease transfusion rates should be employed in clinical practice. 


\section{Abbreviations}

BMI: Body mass index; DVT: Deep vein thrombosis; IRB: Institutional review board; LMWH: Low-molecular-weight heparin; OA: Osteoarthritis; PE: Pulmonary embolism; RA: Rheumatoid arthritis; RBC: Red blood cell; THA: Total hip arthroplasty; TJA: Total joint arthroplasty; TKA: Total knee arthroplasty; TXA: Intravenous tranexamic acid

\section{Acknowledgements}

This work was supported by Jiangsu Provincial Key Research and Development Foundation (BE2016608), National Science Foundation of China (81702151), National Science Foundation of China (81871832), Natura Science Foundation of Jiangsu Province (BK20170121), and Fundamental Research Funds for the Central Universities (021414380306).

\section{Authors' contributions}

QJ contributed substantially to the conception and design of the study. KS, YY, PP, and TJ collected and analyzed the data. TJ wrote the manuscript with support from KS. All authors read and approved the final manuscript.

\section{Funding}

This work was supported by Jiangsu Provincial Key Research and Development Foundation (BE2016608), National Science Foundation of China (81702151), National Science Foundation of China (81871832), Natural Science Foundation of Jiangsu Province (BK20170121), and Fundamental Research Funds for the Central Universities (021414380306).

\section{Availability of data and materials}

The data used to support the findings of this study are available from the corresponding author upon request.

\section{Ethics approval and consent to participate}

This study was approved by the institutional review board (IRB) of Nanjing Drum Tower Hospital (no. 2012029).

\section{Consent for publication}

Not applicable.

\section{Competing interests}

The authors declare that they have no competing interests.

\section{Received: 11 March 2019 Accepted: 8 July 2019}

\section{Published online: 23 July 2019}

\section{References}

1. Slover J, Lavery JA, Schwarzkopf R, lorio R, Bosco J, Gold HT. Incidence and risk factors for blood transfusion in total joint arthroplasty: analysis of a statewide database. J Arthroplast. 2017;32(9):2684-7 e2681. https://doi.org/1 0.1016/j.arth.2017.04.048

2. Menendez ME, Lu N, Huybrechts KF, Ring D, Barnes CL, Ladha K, Bateman BT. Variation in use of blood transfusion in primary Total hip and knee arthroplasties. J Arthroplast. 2016;31(12):2757-63 e2752. https://doi.org/10.1 016/j.arth.2016.05.022.

3. Maempel JF, Wickramasinghe NR, Clement ND, Brenkel IJ, Walmsley PJ. The pre-operative levels of haemoglobin in the blood can be used to predict the risk of allogenic blood transfusion after total knee arthroplasty. Bone Joint J. 2016;98-B(4):490-7. https://doi.org/10.1302/0301-620X.98B4.36245.

4. Browne JA, Adib F, Brown TE, Novicoff WM. Transfusion rates are increasing following total hip arthroplasty: risk factors and outcomes. J Arthroplast. 2013:28(8 Suppl):34-7. https://doi.org/10.1016/j.arth.2013.03.035.

5. Nilsson KR, Berenholtz SM, Garrett-Mayer E, Dorman T, Klag MJ, Pronovost PJ. Association between venous thromboembolism and perioperative allogeneic transfusion. Arch Surg. 2007;142(2):126-32; discussion 133. https://doi.org/10.1001/archsurg.142.2.126.

6. Lyon TD, Tollefson MK, Shah PH, Bews K, Frank I, Karnes RJ, Thompson RH, Habermann EB, Boorjian SA. Temporal trends in venous thromboembolism after radical cystectomy. Urol Oncol. 2018. https://doi.org/10.1016/j.urolonc.2 018.05.015.

7. Ghazi L, Schwann TA, Engoren MC, Habib RH. Role of blood transfusion product type and amount in deep vein thrombosis after cardiac surgery. Thromb Res. 2015;136(6):1204-10. https://doi.org/10.1016/j. thromres.2015.10.041.
8. Aziz F, Lehman E, Blebea J, Lurie F. Postoperative complications after lower extremity arterial bypass increase the risk of new deep venous thrombosis. Phlebology. 2017;33(8):558-66. https://doi.org/10.1177/026 8355517737455

9. Thurn L, Wikman A, Lindqvist PG. Postpartum blood transfusion and hemorrhage as independent risk factors for venous thromboembolism. Thromb Res. 2018;165:54-60. https://doi.org/10.1 016/j.thromres.2018.03.002

10. Richards T, Musallam KM, Nassif J, Ghazeeri G, Seoud M, Gurusamy KS Jamali FR. Impact of preoperative Anaemia and blood transfusion on postoperative outcomes in Gynaecological surgery. PLoS One. 2015;10(7): e0130861. https://doi.org/10.1371/journal.pone.0130861.

11. McGurk KJ, Collier BR, Bradburn EH, Love KM, Lollar DI, Baker CC, Hamill ME. Association between blood transfusion, transfusion setting, and the risk of venous thromboembolism in patients with isolated orthopedic trauma. Am Surg. 2016;82(9):e247-8.

12. Cloney M, Dhillon ES, Roberts H, Smith ZA, Koski TR, Dahdaleh NS Predictors of readmissions and reoperations related to venous thromboembolic events after spine surgery: a single-institution experience with 6869 patients. World neurosurgery. 2018;111:e91-7. https://doi.org/10.1 016/j.wneu.2017.11.168.

13. Purvis TE, Goodwin CR, De la Garza-Ramos R, Ahmed AK, Lafage V, Neuman BJ, Passias PG, Kebaish KM, Frank SM, Sciubba DM. Effect of liberal blood transfusion on clinical outcomes and cost in spine surgery patients. Spine J official journal of the North American Spine Society. 2017;17(9):1255-63. https://doi.org/10.1016/.s.spinee.2017.04.028.

14. Yang SD, Ding WY, Yang DL, Shen Y, Zhang YZ, Feng SQ, Zhao FD. Prevalence and risk factors of deep vein thrombosis in patients undergoing lumbar interbody fusion surgery: a single-center cross-sectional study. Medicine. 2015;94(48):e2205. https://doi.org/10.1097/MD.0000000000002205

15. Wang TY, Sakamoto JT, Nayar G, Suresh V, Loriaux DB, Desai R, Martin JR, Adogwa O, Moreno J, Bagley CA, Karikari IO, Gottfried ON. Independent predictors of 30-day perioperative deep vein thrombosis in 1346 consecutive patients after spine surgery. World Neurosurg. 2015;84(6):160512. https://doi.org/10.1016/j.wneu.2015.07.008.

16. Song $K$, Rong Z, Yao Y, Shen Y, Zheng M, Jiang Q. Metabolic syndrome and deep vein thrombosis after Total knee and hip arthroplasty. J Arthroplast. 2016;31(6):1322-5. https://doi.org/10.1016/j.arth.2015.12.021.

17. Kuperman EF, Schweizer M, Joy P, Gu X, Fang MM. The effects of advanced age on primary total knee arthroplasty: a meta-analysis and systematic review. BMC Geriatr. 2016;16:41. https://doi.org/10.1186/s12877-016-0215-4

18. Zeng Y, Shen B, Yang J, Zhou Z, Kang P, Pei F. Preoperative comorbidities as potential risk factors for venous thromboembolism after joint arthroplasty: a systematic review and meta-analysis of cohort and case-control studies. J Arthroplast. 2014;29(12):2430-8. https://doi.org/10.1016/j.arth.2014.05.018.

19. Barg A, Henninger HB, Hintermann B. Risk factors for symptomatic deepvein thrombosis in patients after total ankle replacement who received routine chemical thromboprophylaxis. J Bone Joint Surg Br. 2011;93(7):921-7. https://doi.org/10.1302/0301-620X.93B7.26257.

20. Gray DH, Mackie CE. The effect of blood transfusion on the incidence of deep vein thrombosis. Austr N Z J Surg. 1983:53(5):439-43.

21. Danninger T, Rasul R, Poeran J, Stundner O, Mazumdar M, Fleischut PM, Poultsides L, Memtsoudis SG. Blood transfusions in total hip and knee arthroplasty: an analysis of outcomes. ScientificWorldJournal. 2014;2014: 623460. https://doi.org/10.1155/2014/623460.

22. Frisch NB, Wessell NM, Charters MA, Yu S, Jeffries JJ, Silverton CD. Predictors and complications of blood transfusion in total hip and knee arthroplasty. J Arthroplast. 2014;29(9 Suppl):189-92. https://doi.org/10.1 016/j.arth.2014.03.048

23. Yu FT, Armstrong JK, Tripette J, Meiselman HJ, Cloutier G. A local increase in red blood cell aggregation can trigger deep vein thrombosis: evidence based on quantitative cellular ultrasound imaging. J Thromb Haemost : JTH. 2011;9(3):481-8. https://doi.org/10.1111/j.1538-7836.2010.04164.x.

24. Zallen G, Moore EE, Ciesla DJ, Brown M, Biffl WL, Silliman CC. Stored red blood cells selectively activate human neutrophils to release IL-8 and secretory PLA2. Shock. 2000;13(1):29-33.

25. Silvain J, Abtan J, Kerneis M, Martin R, Finzi J, Vignalou JB, Barthelemy O, O'Connor SA, Luyt CE, Brechot N, Mercadier A, Brugier D, Galier S, Collet JP, Chastre J, Montalescot G. Impact of red blood cell transfusion on platelet aggregation and inflammatory response in anemic coronary and noncoronary patients: the TRANSFUSION-2 study (impact of transfusion of 
red blood cell on platelet activation and aggregation studied with flow cytometry use and light transmission aggregometry). J Am Coll Cardiol. 2014;63(13):1289-96. https://doi.org/10.1016/j.jacc.2013.11.029.

26. Lee JS, Gladwin MT. Bad blood: the risks of red cell storage. Nat Med. 2010; 16(4):381-2. https://doi.org/10.1038/nm0410-381.

27. Spinella PC, Carroll CL, Staff I, Gross R, Mc Quay J, Keibel L, Wade CE, Holcomb JB. Duration of red blood cell storage is associated with increased incidence of deep vein thrombosis and in hospital mortality in patients with traumatic injuries. Crit Care. 2009;13(5):R151. https://doi.org/10.1186/ cc8050.

28. Mistry JB, Gwam CU, Naziri Q, Pivec R, Abraham R, Mont MA, Delanois RE. Are allogeneic transfusions decreasing in total knee arthroplasty patients? National Inpatient Sample 2009-2013. J Arthroplast. 2018;33(6):1705-12. https://doi.org/10.1016/j.arth.2017.12.014.

29. Everhart JS, Sojka JH, Mayerson JL, Glassman AH, Scharschmidt TJ. Perioperative allogeneic red blood-cell transfusion associated with surgical site infection after Total hip and knee arthroplasty. J Bone Joint Surg Am. 2018;100(4):288-94. https://doi.org/10.2106/JBJS.17.00237.

30. Bini SA, Darbinian JA, Brox WT, Khatod M. Risk factors for reaching the postoperative transfusion trigger in a community primary Total knee arthroplasty population. J Arthroplast. 2018;33(3):711-7. https://doi.org/10.1 016/j.arth.2017.10.029.

31. Yeh JZ, Chen JY, Bin Abd Razak HR, Loh BH, Hao Y, Yew AK, Chia SL, Lo NN, Yeo SJ. Preoperative haemoglobin cut-off values for the prediction of postoperative transfusion in total knee arthroplasty. Knee Surg, Sports Traumatol, Arthrosc : official journal of the ESSKA. 2016;24(10):3293-8. https://doi.org/1 0.1007/s00167-016-4183-1.

32. Petis SM, Lanting BA, Vasarhelyi EM, Naudie DDR, Ralley FE, Howard JL. Is there a role for preoperative iron supplementation in patients preparing for a total hip or total knee arthroplasty? J Arthroplast. 2017;32(9):2688-93. https://doi.org/10.1016/j.arth.2017.04.029.

33. Voorn VM, van der Hout A, So-Osman C, Vliet Vlieland TP, Nelissen RG, van den Akker-van Marle ME, Dahan A, Marang-van de Mheen PJ, van Bodegom-Vos L. Erythropoietin to reduce allogeneic red blood cell transfusion in patients undergoing total hip or knee arthroplasty. Vox Sang. 2016;111(3):219-25. https://doi.org/10.1111/vox.12412.

34. Cherian JJ, Kapadia BH, Issa K, Banerjee S, Mclnerney VK, Harwin SF, Mont MA. Preoperative blood management strategies for total hip arthroplasty. Surg Technol Int. 2013;23:261-6 doi: sti23/37.

35. Kapadia BH, Banerjee S, Issa K, McElroy MJ, Harwin SF, Mont MA. Preoperative blood management strategies for total knee arthroplasty. J Knee Surg. 2013;26(6):373-7. https://doi.org/10.1055/s-0033-1357492.

36. Abdel MP, Chalmers BP, Taunton MJ, Pagnano MW, Trousdale RT, Sierra RJ, Lee YY, Boettner F, Su EP, Haas SB, Figgie MP, Mayman DJ. Intravenous versus topical tranexamic acid in total knee arthroplasty: both effective in a randomized clinical trial of 640 patients. J Bone Joint Surg Am. 2018;100(12): 1023-9. https://doi.org/10.2106/JBJS.17.00908.

37. Li J, Li HB, Zhai XC, Qin L, Jiang XQ, Zhang ZH. Topical use of topical fibrin sealant can reduce the need for transfusion, total blood loss and the volume of drainage in total knee and hip arthroplasty: a systematic review and meta-analysis of 1489 patients. Int J Surg. 2016;36(Pt A):127-37. https:// doi.org/10.1016/j.jijsu.2016.10.022.

38. Churchill JL, Toney VA, Truchan S, Anderson MJ. Using aminocaproic acid to reduce blood loss after primary unilateral total knee arthroplasty. Am J Orthop. 2016;45(5):E245-8.

39. Moo IH, Chen JYQ, Pagkaliwaga EH, Tan SW, Poon KB. Bone wax is effective in reducing blood loss after total knee arthroplasty. J Arthroplast. 2017;32(5): 1483-7. https://doi.org/10.1016/j.arth.2016.12.028.

40. Liodakis E, Antoniou J, Zukor DJ, Huk OL, Epure LM, Bergeron SG. Navigated vs conventional total knee arthroplasty: is there a difference in the rate of respiratory complications and transfusions? J Arthroplast. 2016;31(10):22737. https://doi.org/10.1016/j.arth.2016.03.051.

41. Pawaskar A, Salunke AA, Kekatpure A, Chen Y, Nambi GI, Tan J, Sonawane D, Pathak S. Do autologous blood transfusion systems reduce allogeneic blood transfusion in total knee arthroplasty? Knee Surg, Sports Traumatol, Arthrosc : official journal of the ESSKA. 2017;25(9):2957-66. https://doi.org/10.1007/ s00167-016-4116-z.
42. Leigheb M, Pogliacomi F, Bosetti M, Boccafoschi F, Sabbatini M, Cannas M, Grassi F. Postoperative blood salvage versus allogeneic blood transfusion in total knee and hip arthroplasty: a literature review. Acta Biomed : Atenei Parmensis. 2016;87(Suppl 1):6-14.

43. Dan M, Liu D, Martos SM, Beller E. Intra-operative blood salvage in total hip and knee arthroplasty. J Orthop Surg. 2016;24(2):204-8. https://doi.org/10.11 77/1602400217.

\section{Publisher's Note}

Springer Nature remains neutral with regard to jurisdictional claims in published maps and institutional affiliations.

\section{Ready to submit your research? Choose BMC and benefit from:}

- fast, convenient online submission

- thorough peer review by experienced researchers in your field

- rapid publication on acceptance

- support for research data, including large and complex data types

- gold Open Access which fosters wider collaboration and increased citations

- maximum visibility for your research: over $100 \mathrm{M}$ website views per year

At BMC, research is always in progress.

Learn more biomedcentral.com/submissions 